\title{
Visceral Leishmaniasis: Evaluation of Diagnostic Tools, Therapeutic Regimens, and Associated Risk Factors in Areas with Frequent Outbreaks in South Sudan and Sudan: Case Reports and Review of Literature
} Jacob Kasio Amanya ${ }^{1^{*}}$ and Hong-Juan Peng ${ }^{2}$

${ }^{1}$ School of International Education, Southern Medical University, PR-China

${ }^{2}$ Department of Pathogen Biology, School of Public Health, Southern Medical University, China

"Corresponding author: Jacob Kasio Amanya, Department of Pathogen Biology, School of Public Health, Southern Medical University, Guagndong 1019300, China, Tel: +8613250307047; E-mail: amanyajazy@yahoo.com

Received date: October 08, 2018; Accepted date: November 26, 2018; Published date: December 3, 2018

Copyright: ( 2018 Amanya JK, et al. This is an open-access article distributed under the terms of the Creative Commons Attribution License; which permits unrestricted use; distribution; and reproduction in any medium; provided the original author and source are credited.

\begin{abstract}
Introduction: Visceral leishmaniasis of genus Leishmania donovani is a known cause of Kala-azar, with an agent of Phlebotomus species. Other species of public health importance include Phlebotomus-martini that engulfed South Sudan bordering counties with Kenya whereas Phlebotomus-orientalis dominates northern parts of South Sudan and Sudan. It exhibits rare behavioral characteristics of outer door bites. Among Eastern African countries, South Sudan is a highly endemic area where more than $1 / 3$ of the population is at risks of infections. This review aimed to evaluate the current diagnosis, treatment and risk factors associated with epidemics and mortality due to Visceral Leishmaniasis in Sudan and South Sudan.
\end{abstract}

Methodology and Objective: Literatures published in $\mathrm{SCl}$ Journals, pub med, and science direct, Google, WHO reports, MSF, and CDC websites were searched starting from 1945 to 2018 . Visceral leishmaniasis/VL diagnostic tools, treatment regimens, and associated risk factors were the keywords used during browsing. Details referred to Given Figures in the methodology section.

Findings: Several risk factors contributed to the frequency of VL outbreaks. Chronic wars, malnutrition and settlement in areas infested by the sand fly, co-infections with either HIV or Hepatitis an emerging public health concern. Government efforts to control and eliminates the vectors of VL are lacking with negligible resources allocation. Acacia trees are proved to harbor sand fly as resting and hiding places. K39/K26 or rk39/rk28 dipstick is a field base diagnostic tool commonly used. Treatments with liposomal AmporicinB, sodium stibogluconate plus paromomycin are recommended for use in South Sudan. This review also revealed that areas formerly free from Kala-azar had experience recurrent epidemic.

Conclusion: VL in South Sudan remains highly isolated from clinical diagnosis, treatment, and control strategies. Routine data for surveillance is also an absence. National guidelines and protocols for treatment, and vector control remain at standstill. The level of resistance of visceral Leishmania parasites to the available anti-leishmanial drugs required more researches. There is a close relationship between frequent VL outbreaks and internal conflicts, poor malnutrition, poverty and displacement to high transmission zones, individuals who are new in sand fly infested areas are at greater risks, including children, elderly and pregnant women.

Keywords: Visceral leishmaniasis; South Sudan; Diagnostic; Therapeutic; Risk factors; Kala-azar

Abbreviations: NTDs: Neglected Tropical Diseases; CDC: Centre For Disease Control and Prevention; WHO: World Health Organization; VL: Visceral Leishmaniasis, MSF: Sans Frontiers Medicine; NGO: Non-Governmental Organization; PKDL: Post Kalaazar Dermal Lesions; SFC: Supplementary Feeding Centre

\section{Introduction}

South Sudan and Sudan experience cycle of unrest civil wars, that devastated the living conditions of citizens, displaced millions within and to the neighboring countries [1-3] that possibly contributed to high potential risk of parasitic infections, malnutrition, emerging and re-emerging infectious diseases and associated detrimental risk factors
$[2,4]$, which led to high incidence and prevalence of visceral leishmaniasis/VL [4,5]. However, VL/Kala-azar affect majorly rural dwellers [6], inflicting a systemic latent infection transmitted by infected female sand flies of genus Leishmania [7]. In contrast, the infection is also known as "black sickness/dumdum or Kala-azar" [8]. Its impact is the highest after malaria [9] in rural settings across greater Upper Nile region of South Sudan and Eastern Sudan [10,11]. Furthermore, it ranked on top of Neglected Tropical Diseases (NTDs) in priority listing [12]. Despite this classification, the governments' commitment is lacking, due to insufficient resources allocation for program implementation in combating the disease burden [12]. Ultimately VL remains a devastating health condition among remote populations in endemic counties of greater Upper Nile, Bhar-El ghazel and Kapoeta counties in the Equatorial region [13]. In these areas there is limited access to treatment which is being provided only by an NGO called Medicines Sans Frontiers (MSF), operating in the regions. Due 
to insecurity reasons in the area, patients may sometimes receive no treatment at all $[10,14]$.

Clinically, the disease is characterized by signs including fever, weight loss, fatigue, anemia, and enlargement of liver and spleen, lymph node, mucosa of the small intestine and the respiratory tract $[15,16]$. Regardless of these signs and symptoms, there is also a sudden onset of fever associated with the disease manifestation [16,17] Furthermore, Kala-azar emerged as a top silent killer among NTDs in the World $[18,19]$. It is estimated that $2,00,000-4,00,000$ morbidity cases per annum and 20,000 deaths occur with more than 1 billion people at risk of infection in endemic areas [20].

Among three forms of leishmaniasis, VL is also known for its virulence [20], followed by Cutaneous Leishmaniasis (CL) and Mucocutaneous Leishmaniasis (MCL) respectively [20]. VL and CL predominate in the two Sudan $[7,11,21,22]$. The case fatality of VL could exceed more than $95 \%$ in occurrence within 2 years' time [23] According to the various reports, six endemic countries: namely Brazil, Ethiopia, India, Somalia, South Sudan, and Sudan are observed to contribute $90 \%$ of global disease incidence [24]. According to Al Salem et al. [25], the Eastern African countries of Kenya, South Sudan, Uganda, Sudan, Ethiopia and Somalia are badly stricken by VL in subSaharan Africa, where sand flies densely colonize the region with different subgenera of Phlebotomus, paraphlebotomus, synphlebotomus (martini and celiac), larroussius (Orientalis), ananaphlebotomus (rodhaini) [25]. South Sudan remains a challenging state in achieving the United Nations Sustainable Development Goals (SDGs) priorities [13,24]. It is reported that $4,175 \mathrm{VL}$ cases were reported from South Sudan [24]. Similarly, 3,810 VL and 3,011 CL were contributed by Northern Sudan in the same year [26,27]. Treatment and management of Kala-azar remain a lifesaving tool, the first line treatment in South Sudan is the pentavalent antimonial, Sodium Stibogluconate (SSG) combined with an aminoglycoside, Paromomycin (PM). SSG and PM are basically ambulatory drugs administered intramuscularly daily for 17 days. However, SSG has been associated with toxicity such as gastrointestinal, hepatic and nephrotoxicity [3]. In pregnant women spontaneous abortion [24], is the contraindication. HIV co-infection and VL severe cases are treated with liposomal amphotericin B [28]. Nevertheless, it is not suitable for most African countries since it is more expensive and requires a standard cold chain for storage [3].

Furthermore, Al Salem et al. [25] pointed out that South Sudan rural areas are not only threatened by VL but also other endemic NTDs sparsely distributed in different states across the country, the majority includes but not limited to; human African trypanosomiasis (HAT), onchocerciasis, dracunculiasis, trachoma, working ulcer, leprosy, loa-loa, schistosomiasis and intestinal helminth infections [25].

\section{VL Historical evolution in South Sudan}

In 1904 the first clinical case of VL was isolated from a child in greater Bhar-El Ghazal Province of Southern Sudan [29-31]. Besides between 1984-1994 the world's largest VL epidemic occurred in western Upper Nile region with over 100,000 death estimates [1]. In the early 90s, a third of Southern Sudan population suffered from the burden of Kala-azar [27,29].

Conversely, in 1994-2002 more and more incidences of VL started to shot up specially in Jonglei state counties of Old Fangak and New Fangak in the northern part, as well as in areas of Ayod, Korfulus and
Eastern Upper Nile [32,33] where two consecutive outbreaks occurred, [34] with 17,000 cases $[29,31]$. Even though cases start to decline after the intervention undertaken by MSF-France, the diseases still result in high mortality and morbidity [35] with annual average morbidity estimates of 1,756 [29]. However, the real approximation is anticipated to be within 7,400-14,200 [29]. As a result of the conflict, population access to health care has been cut off and broken down. Though some humanitarian agencies took the risk to reach the needy, the demand for health services remains high (Figure 1) [2].

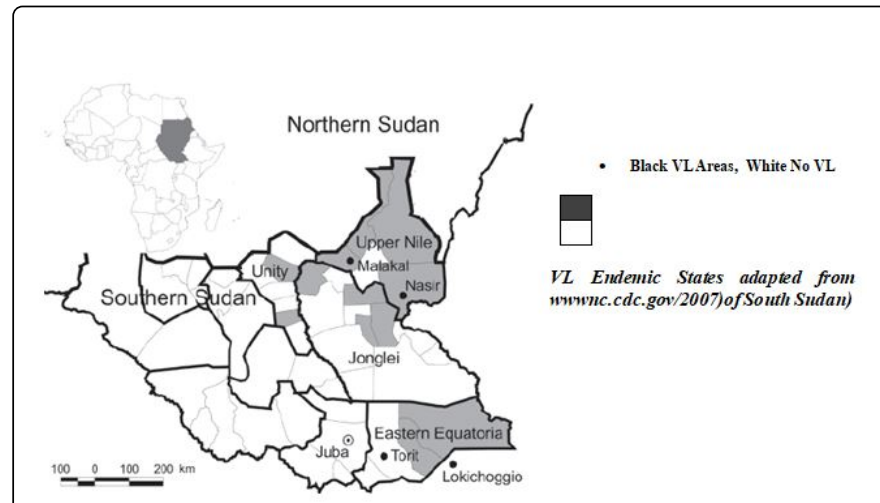

Figure 1: Areas infested by sand flies in South Sudan and Sudan.

Aim: This review is to evaluate the current effective and efficient drugs used in the treatment of visceral leishmaniasis in Sudan and South Sudan, access diagnostic tools that are suitable for the rural areas application and to correlate frequent outbreaks with predisposing factors such as civil war, Malnutrition, poverty, and settlement in sand flies infested areas. Therefore, the frequency of VL outbreaks, high mortality and morbidity cases in South Sudan and Sudan is the reason behind this review article.

Significance: This review will synergize the basic packages of health service in addressing VL control and prevention intervention since it is first of its kind outlining priority areas of interest, not only that but also to assist the local government to prioritize resources to endemic areas. Furthermore, it will assist public health program managers to address health promotion programs specifically targeting VL counties. This review article may play a pivotal role as a basis toward developing a national guideline to assist health partners working in Kala-azar endemic counties to provide treatment and management of cases. Aids and guide decision-makers in directing public health policies, plan interventions and to take actions against VL since it outlined the areas colonize by the sand fly, not only that but also to be used as a stepping block to strengthened routine surveillance in identified areas. Above all, it highlights the main risk factors of dying from VL. However, this reviews also created venues and demand for ecological researchers to find out why the confluence of River Nile and Sobat River in Upper Nile region is a hot cake of VL outbreaks?

\section{Methodology/Search Strategy}

On search engine, in PubMed website the term visceral leishmaniasis was entered and searched, 1,152 articles retrieved, filtered by review articles and duplicates removed, 905 articles were left, filtered again using full-text, free full-text 645 remain considered for further screening and then refine to the title visceral leishmaniasis in East Africa 211 articles left and finally analyzed for VL in South 
Citation: Amanya JK, Peng HJ (2018) Visceral Leishmaniasis: Evaluation of Diagnostic Tools, Therapeutic Regimens, and Associated Risk Factors in Areas with Frequent Outbreaks in South Sudan and Sudan: Case Reports and Review of Literature. J Trop Dis 7: 293. doi: 10.4172/2329-891X.1000293

Page 3 of 9

Sudan and Sudan 34 review articles were fits into the inclusion criteria with more emphases on visceral leishmaniasis, screening tools, therapeutic and risk factors. In Science direct visceral leishmaniasis was searched 9,526 results retrieved then filtered for review articles, 933 stand the chance and further filtered for publication years from 1945-2018 and removing duplicates as well as considering open and free access review articles 23 articles qualified for inclusion into sample size and from the WHO website, CDC, Google VL report for South Sudan data were retrieved and finally CDC, website was also used for other relevant information. Google search was tentatively used. Maps and other figures are adapted from WHO, Google and CDC (Figure 2).

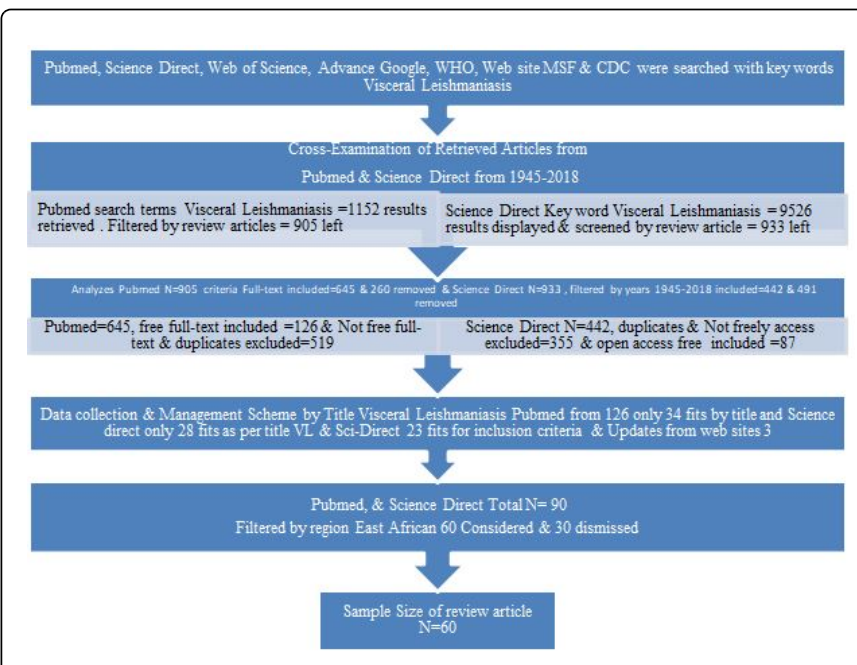

Figure 2: Flow processes of search strategies.

\section{L.D epidemiology and disease occurrence in South Sudan and Sudan}

Sudan and South Sudan are dominated by VL and CL, with a man being a reservoir host [36] quite unique from the Indian type where canine act as reservoirs [7,37].

African Kala-azar, engulf South Sudan and Sudan with rare epidemiological characteristics of disease manifestation from other global types of Kala-azar [38], the distinctive feature is a primary initiation phase in the skin (Leishmanoma) [39] takes time before the onset of clinical symptoms [37]. Utmost importance for epidemiological identification of Sudanese kala-azar [38,39]. L. Donovani occurs in South Sudan, Sudan, and South Western Arabia with 2 forms of VL, CL or MCL [7]. Define by the reservoir of infection of animal or man sometimes both. Local phlebotomine fly occasionally auto infect themselves ingesting amastigote of infected blood tissue [25]. However, the highest frequency of $50 \%$ cases of Oriental sores reported in South Sudan [40]. Its transmission increases in the dry season especially in September and decreases in April and June a seasonal fluctuation tragedy (Table 1) [25].

\begin{tabular}{|c|c|c|}
\hline $\begin{array}{lr}\text { Leishmania } & \text { Main } \\
\text { forms } & \text { and } \\
\text { species } & \end{array}$ & $\begin{array}{l}\text { Disease } \\
\text { Caused }\end{array}$ & Geographical Distribution \\
\hline \multicolumn{3}{|c|}{ 1. Leishmania donovani complex } \\
\hline L. donovani & VL and PKDL & \multirow{2}{*}{$\begin{array}{l}\text { South Sudan and Sudan (Upper, Nile } \\
\text { Darfur, Blue Nile, Bhar-el Ghazal and } \\
\text { Kapeota in Equatoria region }\end{array}$} \\
\hline L. infantum & $\mathrm{VL}$ and $\mathrm{CL}$ & \\
\hline \multicolumn{3}{|c|}{ 2. Leishmania Ethiopica complex } \\
\hline & Diffuse CL & $\begin{array}{l}\text { Ethiopia borders with South Sudan and } \\
\text { Sudan (East Africa) }\end{array}$ \\
\hline
\end{tabular}

Table 1: L. donovani epidemiology.

There are climatic conditions favorable for different strains of Leishmania that run from semi-arid-dry to tropical humid with terrain and altitude equally variable [25]. Huge outbreak reemerged in September 2009 after the Comprehensive Agreement (CPA) possibly due to the influx of returnees with weak immunity [25] climatic factors and malnutrition are part and partial predetermining risk factors for disease infection (Figure 3) [41].

In South Sudan and Sudan, the areas that were free from kala-azar are experiencing recurrent epidemics [41] such as Fangak in Upper Nile, Blue Nile [42] Unity, Jonglei and some part of Eastern Equatoria, where kala-azar pre-existed [43]. In spite of this preexistence status, 28-30 counties stand at a higher risk [44] with more than 2.7 million inhabitants [31]. There are several vectors VL that are of public health importance include; $P$. martini in Kenya and South Sudan while $P$. orientalis found in far north of South Sudan and Sudan [41]. Other forms exist in different parts of the world such as $P$. chinensis in China, $P$. longipalpis in Brazil, and $P$. perniciosus in the Mediterranean, $P$. argentipes [45].

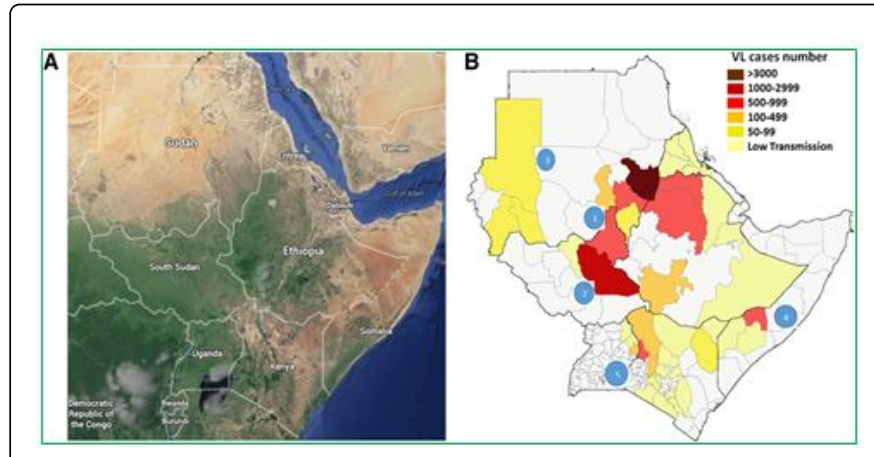

Figure 3: Epidemiology of VL in East Africa.

\section{Diagnosis/ Identification of $L$. donovani}

The morphological characteristic of Leishmania donovani related to the life cycle of the parasite, which led to the clinical condition. It is being categorized into two major developmental stages amastigote and promastigote as indicated in Figure 4. 


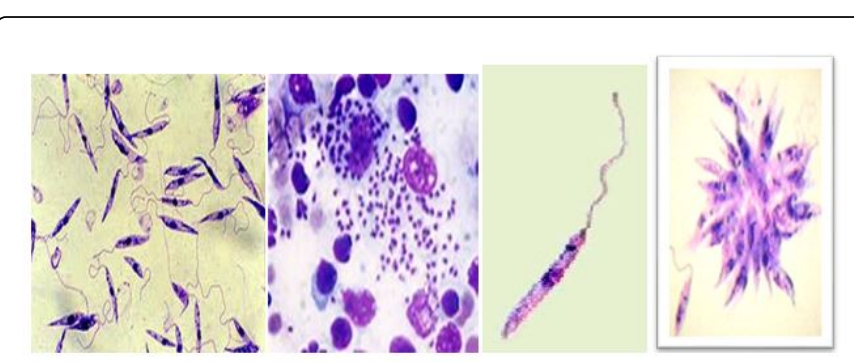

Figure 4: L. donovani diagnosis of amastigote and promastigote stages.

Promastigote (leptomonad): a flagellate occur in vector sand fly and culture media it's infective stage of the parasite, with its size $1.8 \mu \mathrm{m} \times$ $18 \mu \mathrm{m}$ long while the shape is categorized as slender in fuse form and flagellated. However, the structure consists of, nucleus centrally located, kinetoplast in forefront end, and long flagellum at anterior [25].

Amastigote (leishmanial): An a flagellate round, occur in man and animal hosts, non-infective phase, Size $2 \mu \mathrm{m}-4 \mu \mathrm{m}$, shape is oval, nucleus location varies, it's characterized with absence of external flagellum while kinetoplast located next to nucleus and a vacuole known as Leishman Donovan (LD) body that multiplies in man by binary fission. It's commonly found in large mononucleus cells of spleen, liver, and bone marrow even in leucocytes as in lymph nodes (Figure 5).

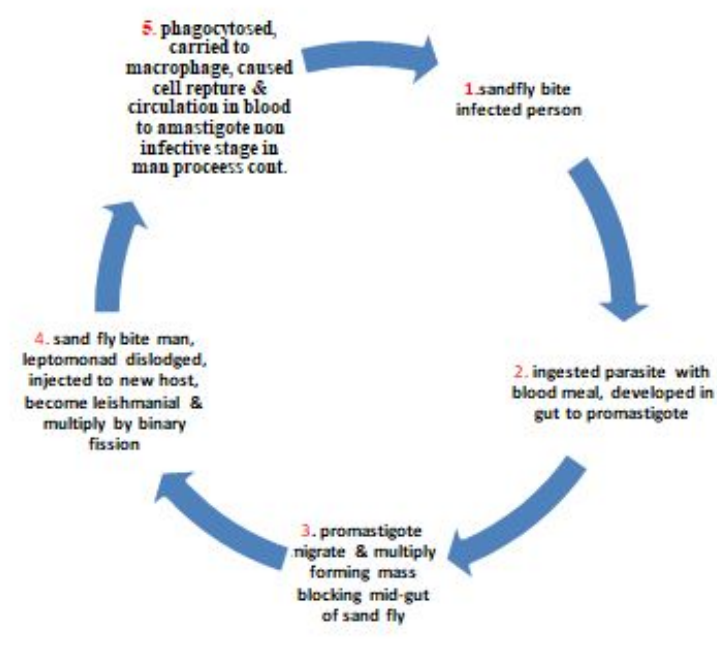

Figure 5: Flow explanation of Leishman Donovan life-cycle.

\section{Pathogenesis of L. donovani and clinical symptoms}

Amastigotes colonize as it parasitizes human macrophages weakening or destroying the macrophages, stimulating proliferation, that forms blockage and destruction of the blood vessels, then after which the parasite migrates to the spleen, liver (visceral) and bone marrow [46]. Consequently resulting in the loss of blood-forming tissues leading to anemia, leucopenia, and bleeding of gum. Therefore, without adequate treatment and management, case fatality rate probably reaches $95 \%$ within 2 years of post-infection [27].

Individuals living in the endemic zone potentially gained some resistance to infection after automatic self-recovery from VL, the partial immunity developed remain beneficial to individuals in endemic areas, especially people whose skin extract tested positive of VL [25] even though, autoimmune is of benefit, the presence of antired blood cells antibodies made it less protective as they attack leucocytes and platelets [47] the transmission of Sudanese kala-azar via blood is a rare phenomenon, as compared to Indian zoonotic form [6].

\section{Post-Kala-azar Dermal Lesion (PKDL)}

Post-Kala-azar Dermal Lesion (PKDL) manifest as consequent of VL infection with a parasite in dermis accessible to sand fly bites $[8,48]$. Even if, PKDL appear after patient's treatment as of recent, cases of visceral leishmaniasis co-infection with HIV and Hepatitis B/C started to surface in South Sudan, Sudan and other Eastern African Countries [5].

Skin Reaction to Pentostam in Kala-azar patient, Post Kala-azar Dermal Lesions (PKDL) (photograph by Peter Moszyski Upper Nile South Sudan MSF 2015).

\section{The incubation period (IP)}

The disease progression varies from 6-20 weeks sometimes 1-2 years contrary to South Sudanese strain with a short interval between 12-16 weeks [26].

\section{Reservoirs}

VL reservoir hosts include; man, rodents, and dogs [49,50].

\section{Clinical symptoms}

Fever, weight loss, fatigue, and anemia are primary stages, accompanied with enlargement of spleen the most common feature then swelling of liver but not as severe as in spleen and lymph nodes; this is the characteristic of African Kala-azar. Meanwhile, Chinese type is well known for causing inflammation of nodes [51]. PKDL skin damage commonly seen on the face, hands, feet and abdomen. Familiar features of "Black Sickness" such as in South Sudan and Sudan as in Figure 6 above [51].

Skin Reaction to Pentostam in Kala-azar patient, Post Kala-azar Dermal Lesions (PKDL) (photograph by Peter Moszyski Upper Nile South Sudan MSF 2015) 
Citation: Amanya JK, Peng HJ (2018) Visceral Leishmaniasis: Evaluation of Diagnostic Tools, Therapeutic Regimens, and Associated Risk Factors in Areas with Frequent Outbreaks in South Sudan and Sudan: Case Reports and Review of Literature. J Trop Dis 7: 293. doi: 10.4172/2329-891X.1000293

Page 5 of 9

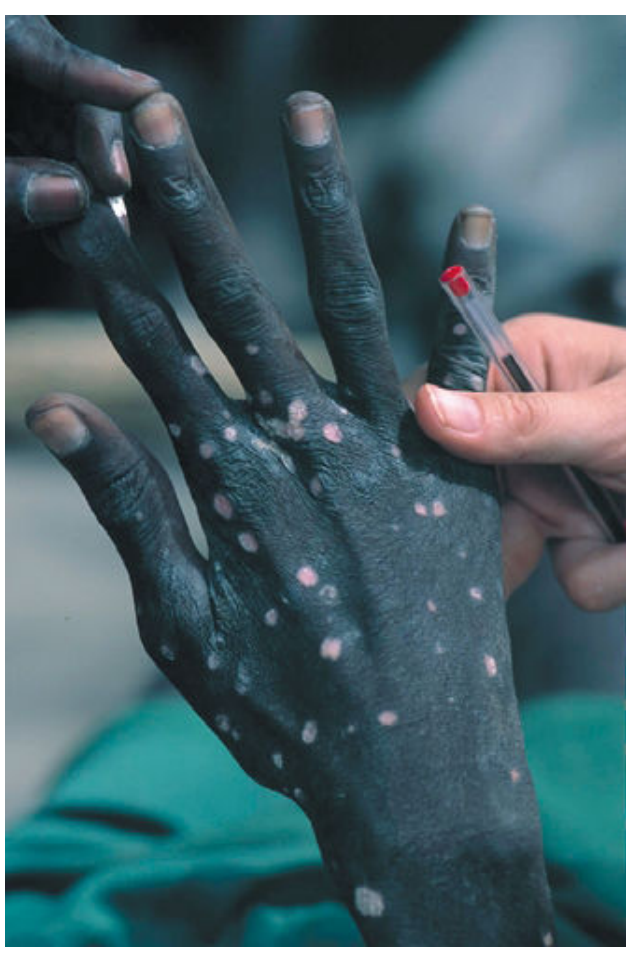

Figure 6: Skin Reaction to Pentostam in Kala-azar patient.

\section{Susceptibility and risk factors}

Susceptibility to infection is universal in all age group even though, more common in adult male than children and women, the frequency of exposure to sand fly bites determines the severity of the risk [26]. In addition to that, the population living in endemic zones stand at higher risk and exposure to infection than those in non-endemic areas [52]. People living with HIV and other immune-compromised person face the risk [24]. Natural responses, re-infection, healing, and posttreatment enhances stable immunity among people living in endemic areas. There are multiple risk factors associated with VL infection such as, anemia, edema, and jaundice; which are the major factors for dying from VL among patients in South Sudan [24]. Furthermore, VL, HIV, Hepatitis B/C co- and multiple-infection coupled with poor response to medication, constitute stereo-typing known to associate with VL. However, of recent some patients from Sudan, South Sudan and neighboring countries of East Africa, were diagnosed with multipleinfections such as HIV, Hepatitis and Kala-azar [24]. VL distribution in terms of age and gender of patients is that the disease is more prevalence among adult males as compared to other sections [31]. These conditions are aggravated by malnutrition, poverty, seasonal variations, and distances $>25 \mathrm{~km}$ from the health facilities as being the key predisposing factors to high mortalities [24]

The old and new world trade link, immigration, opening up new irrigation schemes, mining, and forest lumbering in endemic zones increases the likelihood of new infections [24]. Grazing and cattle camping are major exposure sites to VL with $>85 \%$ cases among South Sudanese Nomadic tribes (Bhar-El Ghazal, Upper Nile, Jonglei and part of Eastern Equatoria) states. The man activities and natural calamities such as environmental, climatic changes, fishing, war, displacement and hunting, settlement patterns, proximity to rivers and areas infested by sand fly [53] play a major role in diseases transmission. Whereas, areas with intense transmission, immunity in majority exist making new arrivals to the area more vulnerable [53].

\section{VL diagnostic tools and criterion}

The rk39 is used by MSF to diagnose cases of VL patients in South Sudan, it is the first line test tool for screening suspected patients, those who tested negative were further screened with leishmania DAT, and also parasitological tests using Giemsa-stain for spleen, liver and lymph node aspirates rarely used. Clinical suspicion is also applied during the absence of diagnostic tools (Figure 7) [54]

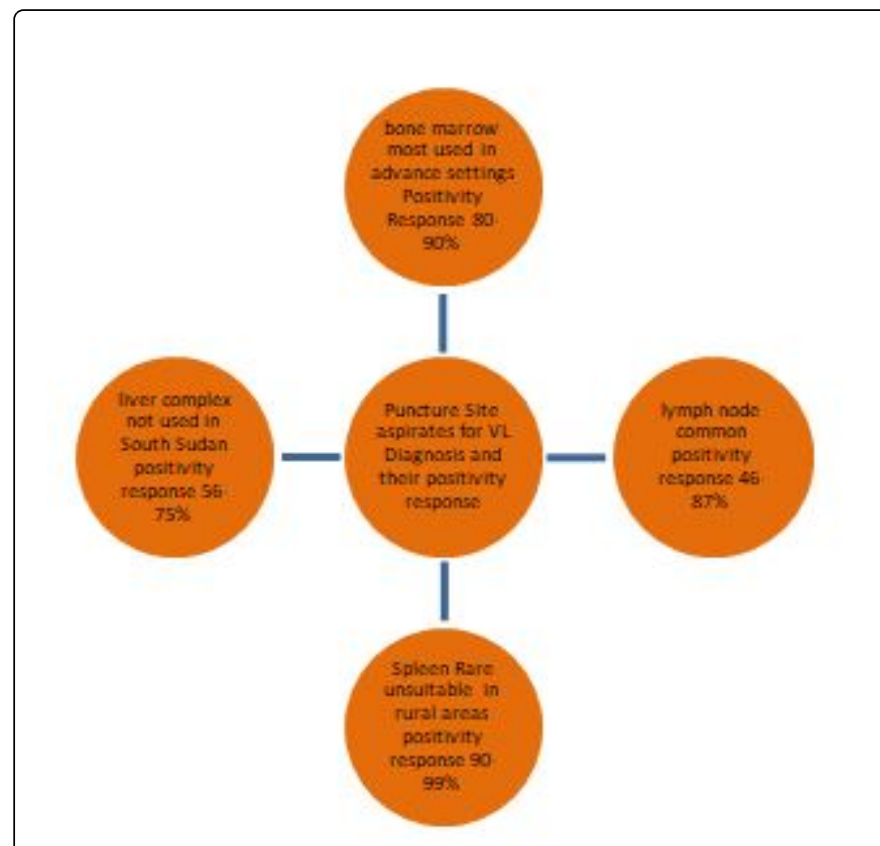

Figure 7: Parasite examination: Direct microscopy and culture media (L.D).

Diagnostic tests include: skin test, the Montenegro skin test, skin biopsy, indirect immunofluorescent antibody test assay, DAT and DNA hybridization plus PCR are the recent modern tools used to further screening and diagnosis of VL cases [55].

\section{Diagnostic tools evaluation}

The parasitological test is suitable for the diagnosis of VL, while culture media of biopsy aspirates is reliable and consistent with HIV and VL co-infection test [14]. Since it detects antibodies rather than parasite [46]. But, it's not suitable in South Sudan and Sudan rural areas due to complexion in using, even though it identifies leishmanial strains of various geographical areas [56]. Another important diagnostic is tool PCR which yields standard results but expensive for rural use. Furthermore, the serological test is difficult to use and labor intensive, requiring competent skills and personnel limiting its demand [46]. While freeze-dried antigen DAT and K39dipstick methods are commonly used in remote settings since they are inexpensive and easy to train semi-literate healthcare workers. This is a Gold standard in South Sudan. Visualization of amastigote in spleen 
aspirate and bone marrow aspirate is not available in endemic areas since it requires skills for operation [56].

\section{Emphasis on diagnosis tools}

Many endemic countries prefer to use serological test and RDT rK39 because they give $92 \%$ positive cases of VL and also indicate correct negative results of up to $92 \%$ of those without the disease. However, $2^{\text {nd }} \mathrm{RDT} /$ Latex agglutination test gave only $64 \%$ correct positive results of those with disease and over $93 \%$ negative results of those with no disease [38].

DAT anti-leishmania, antigen test standardized by MSF in South Sudan is difficult to use and cumbersome, as such it's application is limited whereas, rk35 rapid test use for diagnosing suspected cases of primary VL fall short-cut because of not everyone in endemic areas who became infected need treatment. Whereas serological test only meant for immune response and not for parasite check had limited its application [3]. Another test erythrosalicylic used during emergency response [57].

\section{Diagnosis deduction foot-note}

The examination of the lymph node, spleen, bone marrow aspirate and blood demonstrates parasite (amastigote). However, the parasite commonly isolated in VL, HIV/Hepatitis co- or triple-infection [58]. In some remote areas, a non-specific test of formal gel still used [15] and countercurrent immune-electrophoresis, complement fixation of indirect haemagglutination test. Further still, leishmanin/Montenegro test is an epidemiological tool that measures cell-mediated immunity [5] new technique of monoclonal antibodies, nucleic acid hybridization, and PCR, on most occasions CL reveals positivity between 2-3 months after the disappearance of lesion and finally remains positive in the host lifetime [24] in contrast, MCL test can be done with smears, biopsy, and culture

\section{Treatment and management of VL/Kala-azar}

Individual patient; Sodium Stibogluconate $20 \mathrm{mg} / \mathrm{kg} /$ day in 2 divided doses IM or IVX 28 gold standard for treatment of kala-azar replaced with SSG+PM (sodium stibogluconate+pranomycin) WHO new recommendation for South Sudan, Sudan and Eastern African Countries [59]. SSG monotherapy, $20 \mathrm{mg}$ sb $5+/ \mathrm{kg}$ body weight over 30 days replaced by SSG plus PM combination therapy $20 \mathrm{mg} \mathrm{sb}$ $5+\mathrm{kg} /$ day plus PM $15 \mathrm{mg} / \mathrm{kg} /$ day over 17 days, first-line treatment [11]. Cytokine therapy; activation of the Th1 response of macrophage [60].

Pentavalent antimonial used for primary management of chronic $\mathrm{VL}$, dose $20 \mathrm{mg}$ of sb/kg body weight IM 20 days. VL amphoteric B in the liposomal formulation is used in India only [61]

Miltefosine first-line oral therapy has the cure rate of $95 \%$ in the $3^{\text {rd }}$ trial phase in Ethiopia probably future alternative in Africa; while Liposomal amphotericin B used for severe cases management including, in pregnancy and the HIV co-infection [13,28]. Other drugs available include pentamidine, aminoside, and lipidation used during emergencies situations. VL patients also require nutrition supplement within a supportive therapeutic feeding setting to recover quickly from VL [23].

\section{Prevention and control}

Attacking sand fly and animal reservoirs of infection to break the transmission chain had been successfully applied to control VL. However, early case detection and prompt treatment decrease transmission effects [62], sand fly bites could be avoided by sleeping in the upper floor of houses (only applicable to economically stable states not practical in most African population such as South Sudan) [63].

Repellent-impregnated bed nets and curtains (social structures, cultures, housing types, the habit of sleeping outside houses and sand fly altered behavior for outdoor bite might compromise the effectiveness of nets as the cheapest intervention [35].

According to WHO 2017 report clearing off breeding sites of sand fly and preferable hidings places such as cracks on local walls could possibly lower cases. Not only has that application of IRS and outdoor sprayed with insecticides during the active season of sand fly MaySeptember reduces the densities of sand fly hence decrease in incidence cases and mortality [50]. Tentatively insecticide-impregnated dog collars being developed [50].

Treatment or killing of infected dogs with $L$. infantum had not been successful as asymptomatic seronegative dogs infective to sand fly are available as in Asian countries [50]. The destruction of rodents far from villages was a success story in controlling the leishmaniasis in Uzbekistan and Turmenistian by plowing burrow of rodents deep plow and combining the poison grain with anticoagulants effects [50].

\section{The community}

Avoiding settlement in areas infested by sand fly vectors lower chances of infection as revealed in the studies conducted in South Sudan by Al Salem, W, Herrick et al. [25].

Thornton, S.J, Wasan et al. [40] suggest that termite' hills in endemic areas should not be near household structures by at least 90 meters away because they harbor sand flies. The research further, proposed administration of mass chemotherapy in high endemic areas and supplemented with routine surveillance of VL [54,63]. Newcomers in endemic areas may act as catalyzes to disease outbreak [25]. Breaking the chain of contact between man and sand fly is paramount in controlling VL [63].

\section{Prevention: No vaccine yet approved}

IRS not effective as in L. tropica which is anthroponoticImmunization-inoculation of life in upper arm/ buttocks on trial in endemic areas for years. L. major virulence parasite recommended also to protect against $L$. tropica lesions heal quickly showing promising results trial is ongoing $[25,63]$.

Protection from sand flies an important aspect, by staying indoor during down and dust hours, the vector active hours as to minimized exposure risks to infection while bearing in mind the use of PPE (repellent and long sleeve) [25].

\section{Challenges}

The absence of surveillance data plus vector control guideline for program management is lacking. Even there is less commitment from Government. The situation is worsening by poverty since most rural dwellers live along the poverty line with less than 1 dollar a day (South Bureau of Statistic 2010). The national guideline does not include new strategies for treatment or even lacking pre-existing one. Multi- 
Citation: Amanya JK, Peng HJ (2018) Visceral Leishmaniasis: Evaluation of Diagnostic Tools, Therapeutic Regimens, and Associated Risk Factors in Areas with Frequent Outbreaks in South Sudan and Sudan: Case Reports and Review of Literature. J Trop Dis 7: 293. doi: 10.4172/2329-891X.1000293

Page 7 of 9

existence of the host is challenging in control and prevention of VL [25]. Unfortunately, impregnated nets meant for prevention yield little success as the vector bites outdoor contradictory to night use of bed nets [25] while mass chemotherapy is difficult due to inaccessibility of the areas, insecurity and frequent civil wars in endemic states of South Sudan and Southern Kordufan in Sudan [25]. Logistical supply is only by chartered plane, limiting distribution of essential supply. Once more, the confluence of Sobat and river Nile at the high endemic angle in greater Upper Nile possibly facilitated as a source of transmission density [63]. Nevertheless, the ecological link of Sobat River from Ethiopia to South Sudan and river Nile from Uganda requires extensive ecological studies [58].

\section{Pre-existing interventions}

Various UN agencies and NGOs working in Sudan and South Sudan, to implement public health programs targeted to reduce the incidence of VL, majorly in case management, epidemiological surveillance and prompt treatment of cases in coordination with host Government [25].

\section{Conclusion}

Visceral leishmaniasis is an NTD that had greatly brought the heaviest burden of mortality and morbidity after malaria in South Sudan and Sudan. However, areas known free off the disease had recently witnessed cases of kala-azar spotted in a different location of Greater Bhar el Ghazal, Upper Nile and Equatoria of Southern Sudan region while new cases also being reported in Durfur in the region of Northern Sudan (Figure 8).

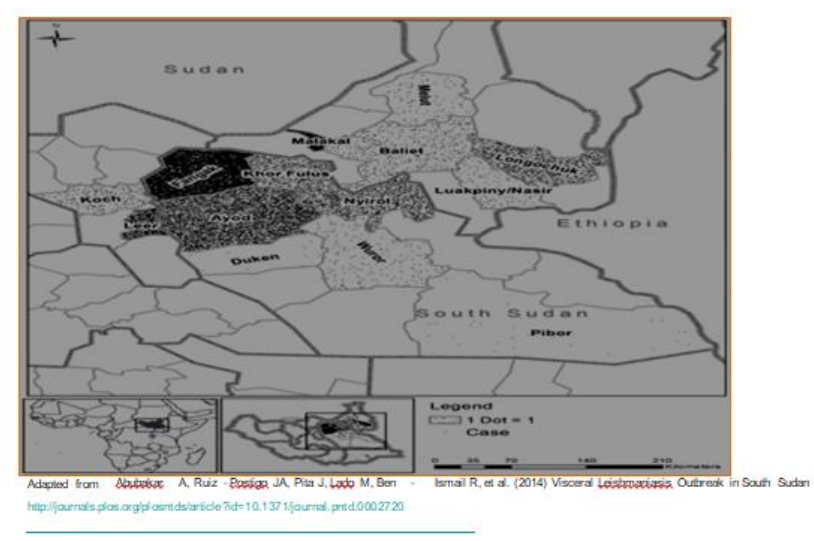

Figure 8: Geographical distribution of visceral leishmaniasis cases by counties in South Sudan.

Majority of cases of VL in South Sudan remain highly isolated from clinical diagnosis, treatment, and control even routine data for surveillance system of the disease is far from the practical reality of monitoring and evaluation aspects while the national guideline and protocols for treatment, management and vector control remain at standstill for future prospective towards developing;

The resistance of visceral leishmania to drugs either at static or in an increasing level required more in-depth scientific research and expertise. Leishmaniasis vector flight range from the ground floor is extremely low. This characteristic could possibly be used during intervention sessions. Confluence point of Sobat and river Nile requires extensive ecological studies.

\section{Acknowledgment}

I am highly indebted to Prof. Hong-Juan Peng, Director of Pathogen Biology Southern Medical University for guidance and to my close friends Iduho Esther, Mike, Mercy and Harriet Amanya, I dedicated this humble work to all of you, without you, I would have not achieved all that it takes review paper.

\section{References}

1. Veeken H (1998) Sudan, through the back door. Ned Tijdschr Geneeskd 142: 1781-1785.

2. Abubakar A, Ruiz-Postigo JA, Pita J, Lado M, Ben-Ismail R (2014) Visceral leishmaniasis outbreak in South Sudan 2009-2012: epidemiological assessment and impact of a multisectoral response. PLoS Negl Trop Dis 8: e2720.

3. Abongomera C, Gatluak F, Buyze J, Ritmeijer K (2016) A comparison of the effectiveness of sodium stibogluconate monotherapy to sodium stibogluconate and paromomycin combination for the treatment of severe post-kala-azar dermal leishmaniasis in south sudan-a retrospective cohort study. PLoS One 11: e0163047.

4. Ahmed MA, Suleman SM, Kordofani AA, Mustafa MD (1988) Outbreak of visceral leishmaniasis in the western bank of the White Nile-Sudan, report and clinical study. East Afr Med J 65: 824-828.

5. Eichenberger A, Buechi AE, Neumayr A, Hatz C, Rauch A (2017) A severe case of visceral leishmaniasis and liposomal amphotericin B treatment failure in an immunosuppressed patient 15 years after exposure. BMC Infect Dis 17: 81.

6. Baleela R, Llewellyn MS, Fitzpatrick S, Kuhls K, Schönian G, et al. (2014) Leishmania donovani populations in Eastern Sudan: temporal structuring and a link between human and canine transmission. Parasit Vectors 7: 496.

7. Mahamoud A, Osman HA, Abass EM, El Agib A, Madi RR, et al. (2018) Identification of an area predominantly endemic for childhood and adolescent visceral leishmaniasis in central Sudan. Acta Trop 178: 142-147.

8. El Hassan AM, Khalil EA, Elamin WM, El Hassan LA, Ahmed ME, et al. (2013) Misdiagnosis and mistreatment of post-kala-azar dermal leishmaniasis. Case Rep Med 2013: 351579.

9. Adegboye OA, Al-Saghir M, Leung DH (2017) Joint spatial time-series epidemiological analysis of malaria and cutaneous leishmaniasis infection. Epidemiol Infect 145: 685-700.

10. Mercer A, Seaman J, Sondorp E (1995) Kala azar in eastern Upper Nile Province, southern Sudan. Lancet 345: 187-188.

11. Melaku Y, Collin SM, Keus K, Gatluak F, Ritmeijer K, et al. (2007) Treatment of kala-azar in southern Sudan using a 17-day regimen of sodium stibogluconate combined with paromomycin: a retrospective comparison with 30-day sodium stibogluconate monotherapy. Am J Trop Med Hyg 77: 89-94.

12. Moszynski P (2002) Health organisation warns that kala-azar has returned to South Sudan. Lancet 360: 1672.

13. Gulland A (2002) Deadly parasitic disease grips southern Sudan. BMJ 325: 1133b-1133.

14. van den Bogaart E, Talha AB, Straetemans M, Mens PF, Adams ER (2014) Cytokine profiles amongst Sudanese patients with visceral leishmaniasis and malaria co-infections. BMC Immunol 15: 16.

15. Mukhtar M, Abdoun A, Ahmed AE, Ghalib H, Reed SG, et al. (2015) Diagnostic accuracy of rK28-based immunochromatographic rapid diagnostic tests for visceral leishmaniasis: a prospective clinical cohort study in Sudan. Trans R Soc Trop Med Hyg 109: 594-600.

16. Mukhtar M, Ali SS, Boshara SA, Albertini A, Monnerat S, et al. (2018) Sensitive and less invasive confirmatory diagnosis of visceral 
Citation: Amanya JK, Peng HJ (2018) Visceral Leishmaniasis: Evaluation of Diagnostic Tools, Therapeutic Regimens, and Associated Risk Factors in Areas with Frequent Outbreaks in South Sudan and Sudan: Case Reports and Review of Literature. J Trop Dis 7: 293. doi: 10.4172/2329-891X.1000293

Page 8 of 9

leishmaniasis in Sudan using loop-mediated isothermal amplification (LAMP). PLoS Negl Trop Dis 12: e0006264.

17. Zijlstra EE, Ali MS, el-Hassan AM, el-Toum IA, Satti M (1992) Clinical aspects of kala-azar in children from the Sudan: a comparison with the disease in adults. J Trop Pediatr 38: 17-21.

18. Rougeron V, De Meeûs T, Hide M, Le Falher G, Bucheton B, et al. (2011) Multifaceted population structure and reproductive strategy in Leishmania donovani complex in one Sudanese village. PLoS Negl Trop Dis 5: el448.

19. Sunyoto T, Adam GK, Atia AM, Hamid Y, Babiker RA, et al. (2018) KalaAzar is a dishonest disease: Community perspectives on access barriers to visceral leishmaniasis (Kala-Azar) diagnosis and care in Southern Gadarif, Sudan. Am J Trop Med Hyg 98: 1091-1101.

20. Mueller YK, Nackers F, Ahmed KA, Boelaert M, Djoumessi JC, et al. (2012) Burden of visceral leishmaniasis in villages of eastern Gedaref State, Sudan: an exhaustive cross-sectional survey. PLoS Negl Trop Dis 6: e1872.

21. Kordofani Y, Nour Y, El-Hassan AM, Shalayel MH (2001) Post kala azar dermal leishmaniasis in Sudan. East Mediterr Health J 7: 1061-1064.

22. Mohammed MA, Khalid NM, Aboud MA (2018) Kala-azar in Darfur: Evidence for indigenous transmission in Al-Malha Locality, North Darfur, western Sudan. Parasit Vectors 11: 149.

23. Meheus F, Abuzaid AA, Baltussen R, Younis BM, Balasegaram M, et al. (2013) The economic burden of visceral leishmaniasis in Sudan: an assessment of provider and household costs. Am J Trop Med Hyg 89: 1146-1153.

24. Kämink SS1,2, Collin SM3, Harrison T4, Gatluak F4, Mullahzada AW, et al. (2017) A clinical severity scoring system for visceral leishmaniasis in immunocompetent patients in South Sudan. PLoS Negl Trop Dis 11: e0005921.

25. Al-Salem W, Herricks JR, Hotez PJ (2016) A review of visceral leishmaniasis during the conflict in South Sudan and the consequences for East African countries. Parasit Vectors 9: 460.

26. Idris M, Farid J, Gul N, Anis-ur-Rehman (2010) Visceral leishmaniasis: adult population of Abbottabad at risk now. J Ayub Med Coll Abbottabad 22: $214-215$

27. Adam GK, Ali KM, Abdella YH, Omar SM, Ahmed MA, et al. (2016). Trend in cumulative cases and mortality rate among visceral leishmaniasis patients in Eastern Sudan: a 14-year registry, 2002-2015. Int J Infect Dis 51: 81-84.

28. Salih NA, van Griensven J, Chappuis F, Antierens A, Mumina A, et al. (2014) Liposomal amphotericin B for complicated visceral leishmaniasis (kala-azar) in eastern Sudan: how effective is treatment for this neglected disease? Trop Med Int Health 19: 146-152.

29. Van Peenen PF, Reid TP (1963) Leishmaniasis in the sudan republic 15 an outbreak of kala azar in the khor falus area, upper nile province. J Trop Med Hyg 66: 252-254

30. Zeese W, Frank W (1987) Present epidemiological situation of kala-azar in the Republic of Sudan. Zentralbl Bakteriol Mikrobiol Hyg A 264(3-4): 414-421.

31. Gorski S, Collin SM, Ritmeijer K, Keus K, Gatluak F, et al. (2010) Visceral leishmaniasis relapse in Southern Sudan (1999-2007): A retrospective study of risk factors and trends. PLoS Negl Trop Dis 4: e705.

32. el Hassan AM, Hashim FA, Abdullah M, Zijlstra EE, Ghalib HW (1993) Distinguishing post-kala-azar dermal leishmaniasis from leprosy: Experience in the Sudan. Lepr Rev 64: 53-59.

33. Zijlstra EE, Siddig Ali M, el-Hassan AM, Hofland HW, el-Toum IA, et al. (1993). The treatment of kala-azar in the Sudan with sodium stibogluconate: a randomized trial of three dosage regimens. Trans R Soc Trop Med Hyg 87: 307-309.

34. Van Peenen PF, Reid TP (1962) Leishmaniasis in the Sudan Republic VI Clinical and laboratory aspects of kala-azar in hospitalized patients from Upper Nile Province. Am J Trop Med Hyg 11: 723-730.
35. Collin SM, Coleman PG, Ritmeijer K, Davidson RN (2006) Unseen Kalaazar deaths in south Sudan (1999-2002). Trop Med Int Health 11: 509-512.

36. Khalid NM, Aboud MA, Alrabba FM, Elnaiem DE, Tripet F (2012) Evidence for genetic differentiation at the microgeographic scale in Phlebotomus papatasi populations from Sudan. Parasit Vectors 5: 249.

37. Marquet S, Bucheton B, Reymond C, Argiro L, El-Safi SH, et al. (2017) Exome Sequencing identifies two variants of the alkylglycerol monooxygenase gene as a cause of relapses in visceral leishmaniasis in children, in Sudan. J Infect Dis 216: 22-28.

38. Ghosh I, Sardar T, Chattopadhyay J (2017) A mathematical study to control visceral leishmaniasis: An application to South Sudan. Bull Math Biol 79: 1100-1134.

39. Khalil EA, Musa AM, Younis BM, Elfaki ME, Zijlstra EE, et al. (2011) Blindness following isceral leishmaniasis: A neglected post-kala-azar complication. Trop Doct 41: 139-140.

40. Thornton SJ, Wasan KM, Piecuch A, Lynd LL, Wasan EK (2010). Barriers to treatment for visceral leishmaniasis in hyperendemic areas: India, Bangladesh, Nepal, Brazil and Sudan. Drug Dev Ind Pharm 36: 1312-1319.

41. Bezuneh A, Mukhtar M, Abdoun A, Teferi T, Takele Y, et al. (2014) Comparison of point-of-care tests for the rapid diagnosis of visceral leishmaniasis in East African patients. Am J Trop Med Hyg 91: 1109-1115.

42. Sixl WB, Abdel-Nabi SO, Sebek Z (1989) Contribution to the problems of the diagnostics of leishmaniosis in south-Sudan. Geogr Med Suppl 5: 189-203.

43. Ashford RW, Seaman J, Schorscher J, Pratlong F (1989) Epidemic visceral leishmaniasis in southern Sudan. Lancet 2: 1222-1223.

44. Nishioka Sde A (1997) Visceral leishmaniasis in southern Sudan. Ann Intern Med 126: 332

45. Bhattacharyya T, Bowes DE, El-Safi S, Sundar S, Falconar AK, et al (2014) Significantly lower anti-Leishmania IgG responses in Sudanese versus Indian visceral leishmaniasis. PLoS Negl Trop Dis 8: e2675.

46. Abass E, Mahamoud A, Mansour D, Mohebali M, Harith EA (2011) Validation of a beta-ME ELISA for detection of anti Leishmania donovani antibodies in Eastern Sudan. Iran J Immunol 8: 150-158.

47. Babiker AM, Ravagnan S, Fusaro A, Hassan MM, Bakheit SM , et al. (2014). Concomitant infection with Leishmania donovani and L. major in Single Ulcers of Cutaneous Leishmaniasis Patients from Sudan. J Trop Med 2014: 170859 .

48. Farouk S, Salih MA, Musa AM, Blackwell JM, Miller EN (2010) Interleukin 10 gene polymorphisms and development of post kala-azar dermal leishmaniasis in a selected sudanese population. Public Health Genomics 13: 362-367.

49. Andresen K, Gasim S, Elhassan AM, Khalil EA, Barker DC, et al. (1997) Diagnosis of visceral leishmaniasis by the polymerase chain reaction using blood, bone marrow and lymph node samples from patients from the Sudan. Trop Med Int Health 2: 440-444.

50. Hassan MM, Osman OF, El-Raba'a FM, Schallig HD, Elnaiem DE (2009) Role of the domestic dog as a reservoir host of Leishmania donovani in eastern Sudan. Parasit Vectors 2: 26.

51. Trindade MA, Silva LL, Braz LM, Amato VS, Naafs B, et al. (2015) Postkala-azar dermal leishmaniasis and leprosy: Case report and literature review. BMC Infect Dis 15: 543.

52. Iboi E, Okuneye K, Sharomi O, Gumel AB (2018) Comments on a mathematical study to control visceral leishmaniasis: An application to South Sudan. Bull Math Biol 80: 825-839.

53. Hashim FA, Ali MS, Satti M, el-Hassan AM, Ghalib HW, et al. (1994) An outbreak of acute kala-azar in a nomadic tribe in western Sudan: features of the disease in a previously non-immune population. Trans R Soc Trop Med Hyg 88: 431-432.

54. Adam GK, Omar SM, Ahmed MA, Abdallah TM, Ali AA (2018) Crosssectional study of the case-fatality rate among patients with visceral 
Citation: Amanya JK, Peng HJ (2018) Visceral Leishmaniasis: Evaluation of Diagnostic Tools, Therapeutic Regimens, and Associated Risk Factors in Areas with Frequent Outbreaks in South Sudan and Sudan: Case Reports and Review of Literature. J Trop Dis 7: 293. doi: $10.4172 / 2329-891 X .1000293$

Page 9 of 9

leishmaniasis infections during pregnancy in Sudan. Int J Gynaecol Obstet 140: 119-120.

55. Osman OF, Kager PA, Zijlstra EE, el-Hassan AM, Oskam L (1997) Use of PCR on lymph-node sample as test of cure of visceral leishmaniasis. Ann Trop Med Parasitol 91: 845-850.

56. Abass E, Kang C, Martinkovic F, Semiao-Santos SJ, Sundar SP, et al. (2015) Heterogeneity of Leishmania donovani parasites complicates diagnosis of visceral leishmaniasis: comparison of different serological tests in three endemic regions. PLoS One 10: e0116408.

57. Abass E, Bollig N, Reinhard K, Camara B, Mansour D, et al. (2013) rKLO8, a novel Leishmania donovani-derived recombinant immunodominant protein for sensitive detection of visceral leishmaniasis in Sudan. PLoS Negl Trop Dis 7: e2322.

58. Delacour H, Roche C, Roche B, Morand C, Koeck JL (2010) A travel misadventure-visceral leishmaniasis in an immunocompetent patient. J R Army Med Corps 156: 169-171.

59. Khalil EA, Weldegebreal T, Younis BM, Omollo R, Musa AM (2014) Safety and efficacy of single dose versus multiple doses of AmBisome for treatment of visceral leishmaniasis in eastern Africa: a randomised trial. PLoS Negl Trop Dis 8: e2613.

60. Musa AM, Khalil EA, Younis BM, Elfaki ME, Elamin MY, et al. (2013) Treatment-based strategy for the management of post-kala-azar dermal leishmaniasis patients in the Sudan. J Trop Med 2013: 708391.

61. Atia AM, Mumina A, Tayler-Smith K, Boulle P, Alcoba G, et al. (2015) Sodium stibogluconate and paromomycin for treating visceral leishmaniasis under routine conditions in eastern Sudan. Trop Med Int Health 20: 1674-1684.

62. Griekspoor A, Sondorp E, Vos T (1999) Cost-effectiveness analysis of humanitarian relief interventions: visceral leishmaniasis treatment in the Sudan. Health Policy Plan 14: 70-76.

63. Biswas S, Subramanian A, ELMojtaba IM, Chattopadhyay J, Sarkar RR, (2017) Optimal combinations of control strategies and cost-effective analysis for visceral leishmaniasis disease transmission. PLoS One 12 e0172465. 